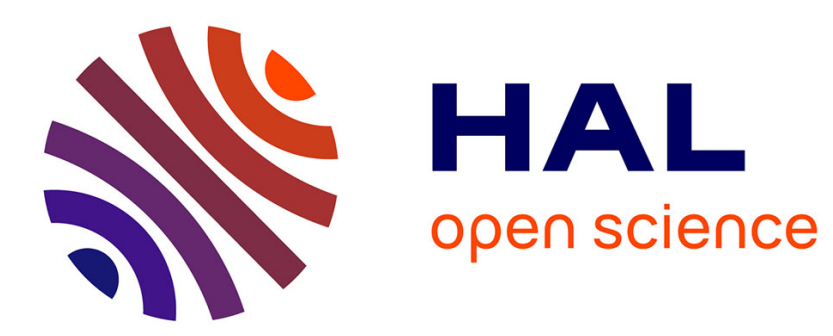

\title{
INTERACTION OF 20-100 MeV/u HEAVY IONS WITH COLD MATTER
}

\author{
J. Herault, R. Bimbot, H. Gauvin, R. Anne, G. Bastin, F. Hubert
}

\section{To cite this version:}

J. Herault, R. Bimbot, H. Gauvin, R. Anne, G. Bastin, et al.. INTERACTION OF 20-100 MeV/u HEAVY IONS WITH COLD MATTER. International Workshop on Atomic Physics for Ion Driven Fusion 4, 1988, Orsay, France. pp.C7-33-C7-42, 10.1051/jphyscol:1988704 • jpa-00228188

\section{HAL Id: jpa-00228188 https://hal.science/jpa-00228188}

Submitted on 1 Jan 1988

HAL is a multi-disciplinary open access archive for the deposit and dissemination of scientific research documents, whether they are published or not. The documents may come from teaching and research institutions in France or abroad, or from public or private research centers.
L'archive ouverte pluridisciplinaire HAL, est destinée au dépôt et à la diffusion de documents scientifiques de niveau recherche, publiés ou non, émanant des établissements d'enseignement et de recherche français ou étrangers, des laboratoires publics ou privés. 
J. HERAULT, R. BIMBOT, H. GAUVIN, R. ANNE*, G. BASTIN ${ }^{*}$ and

F. HUBERT ${ }^{* * *}$

Institut de Physique Nucléaire, BP 1, F-91406 orsay Cedex, France

*GANIL, BP 5027, F-14021 Caen, France

* "CSNSM, BP 1, F-91406 orsay Cedex, France

** CENBG, Le Haut Vigneau, F-33170 Gradignan, France

Résume : Les pouvoirs d'arrêt de 12 solides et de 10 gaz, et les fluctuations des pertes d'energies, ont ete mesurés a l'accelerateur GANIL pour les ions ${ }^{16-17} \mathrm{O},{ }^{40} \mathrm{Ar},{ }^{40} \mathrm{Ca},{ }^{84-86} \mathrm{Kr},{ }^{100}$ Mo et ${ }^{129-132} \mathrm{Xe}$ dans le domaine d'energie 24 à $95 \mathrm{MeV} / \mathrm{u}$. Après une description rapide de la méthode experimentale, un ensemble de résultats est présenté et discuté Il est montre, en particulier, que lorsque le projectile tend a être totalement epluche, une parametrisation simple déduite des pouvoirs d'arret des ions ${ }^{4} \mathrm{He}^{++}$a meme vitesse devient applicable pour le calcul des pouvoirs d'arrêt des ions lourds. Simultanement l'effet solide-gaz, observé a basse energie, tend a disparaitre.

Les fluctuations des pertes d'energie ont ete comparees aux valeurs deduites du modele de Bohr et du modele plus complet de Titeica. Quand le projectile est totalement epluche, les valeurs theoriques restent trop petites d'un facteur 2. Pour des ions partiellement épluchés ce desaccord augmente mais il apparait, dans la dispersion des pertes d'énergie, que la composante liee aux fluctuations des echanges de charge pourrait expliquer les observations expérimentales.

Abstract : The stopping powers of 12 solids and 10 gases and the associated energy loss straggling have been measured at GANIL for ${ }^{16-17} \mathrm{O}$, ${ }^{40} \mathrm{Ar},{ }^{40} \mathrm{Ca},{ }^{84-86} \mathrm{Kr},{ }^{100} \mathrm{Mo}$ and ${ }^{129-132} \mathrm{Xe}$ ions in the energy domain 24 to $95 \mathrm{MeV} / \mathrm{u}$. After a brief description of the experimental method, the set of data are presented and discussed. As far as stopping powers are concerned, a scaling law in $\mathrm{Z}^{2}$ relative to the ${ }^{4} \mathrm{He}$ stopping powers at the same velocity becomes ap fully stripped. At the same time, the solid-gas effect, observed at low energy, vanishes. The energy loss straggling is compared to that deduced from Bohr model and some of its refinements. The theoretical value appears to be too small, by a factor 2, when the projectile is fully stripped. For partially stripped ions, the charge exchange straggling might explain the experimental observation.

\section{INTRODUCTION}

The study of heavy particle penetration through matter is important for nuclear physics in connection with the analysis of experiments. The penetration also provides information on the stopping process itself. Up to now, data concerning stopping power, energy loss straggling and angular straggling were very scarce in the intermediate enexgy domain from 20 to $100 \mathrm{MeV} / \mathrm{u}$. This energy domain is of great interest because it corresponds to a simplification of the slowing down process when the projectile tends to be totally stripped and the relativistic effects are still minor. 
This talk sumarizes the results of an experimental study of heavy ions penetration undertaken at the GANIL national facility/l/. Results concerning stopping powers and energy loss straggling in solids and gases will be given. The angular straggling results have been published recent $1 y / 2 /$.

\section{EXPERIMENTAC SET-UP}

\subsection{Energy measurements}

The energy measurements presented in this work have been performed at GANIL, using the LISE magnetic spectrometer /3/. The magnetic rigidity (Bp) of the incident beam is determined with a relative uncertainty of $\pm 10^{-4}$ using the beam monochromator situated at the exit of the machine.

The incoming beam is focused onto the target $T$ using four quadrupoles lenses $q_{1}$ to $q_{4}$ (see Figure 1 ). Beam profiles are registered by gas filled or secondary emission multiwire detectors (according to the beam intensity).

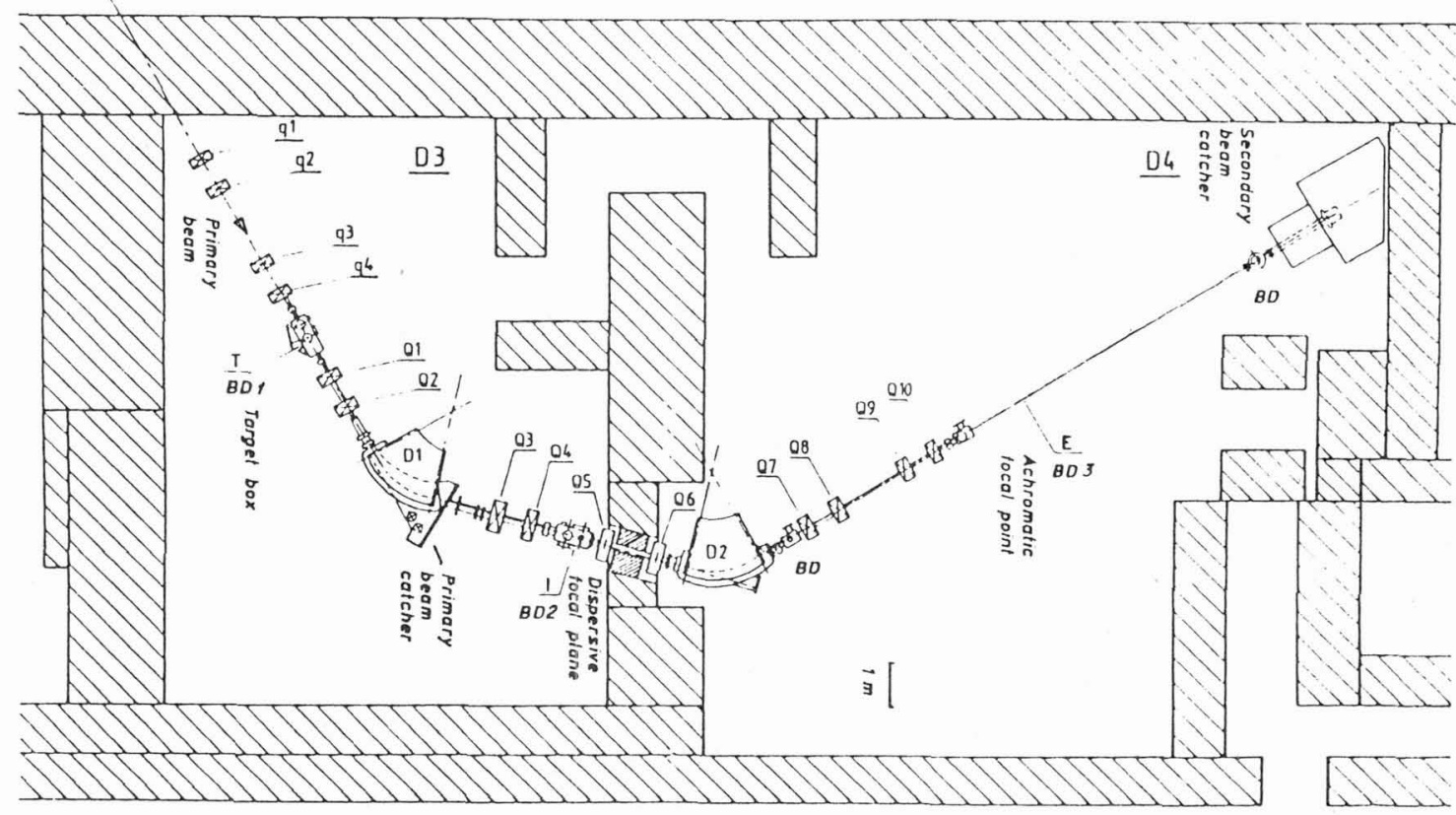

Fig. I : General lay-out of the LISE spectrometer. T is the target position, I the intermediate focal plane and $E$ the final achromatic focus point. The symbols $\mathrm{BDI}-2-3$ indicate the beam diagnostics.

The energy measurements are made using the first part of the spectrometer LISE, with a setting of quadrupoles $Q_{1}, Q_{2}, Q_{3}, Q_{4}$ and dipole $D_{1}$ which ensures a dispersive relation between the object focal plane $T$ (target box) and the image focal plane $I / 3,4 /$. 


\subsection{Targets}

\subsubsection{Solid targets}

Targets of ten elements from Be to Au have been used as degraders. All these targets have been prepared from commercially available material with purity higher than $99 \%$. Mylar films have also been used as targets. The thickness of each sample is determined by the ratio of weight to area. The mean target thickness is thus determined with a precision of about $\pm 1 \% / 4 /$.

\subsubsection{Gaseous targets}

The measurements relative to gaseous media were performed by introducing a closed gas cell into the target box $T$. The nickel windows of the cell have $a$ diameter of $8 \mathrm{~mm}$ and a thickness between 0.9 and $4.5 \mathrm{mg} . \mathrm{cm}^{-2}$ depending on the pressure used. The beam path length inside the gas cell is $14 \mathrm{~cm}$. The cell is filled at a gas pressure of 100 to $5000 \mathrm{hPa}$ which is measured with a precision better than $\pm 1 \mathrm{hPa}$ using an absolute pressure sensor. The temperature is measured in the cell by a Pt 100 gauge with a precision better than $\pm 0.1^{\circ} \mathrm{C}$. The uncertainty in gas thickness which arises from temperature and pressure measurements is less than $\pm 1 \%$. Eleven gases $\left(\mathrm{H}_{2}, \mathrm{He}, \mathrm{N}_{2}, \mathrm{Ar}, \mathrm{Kr}, \mathrm{Xe}, \mathrm{CO}_{2}, \mathrm{CF}_{4}, \mathrm{CH}_{4}\right.$, $\mathrm{C}_{4} \mathrm{H}_{10}$ ) commercially produced with a purity higher than $99.99 \%$ have been used as absorbers.

\section{STOPRING POWERS}

\subsection{Experimental}

The principle of the method is to measure accurately the energy loss $\Delta E$ of ions in a target of given thickness. The measurements of incident $\left(E_{i}\right)$ and degraded energy $\left(E_{f}\right)$ are made using the magnetic spectrometer LISE. The stopping power (S) is derived from these measurements through the approximation

$$
S(E)=-\frac{d E}{d x} \approx \frac{\Delta E}{x}=\frac{E_{i}-E_{f}}{x}
$$

in which $\mathrm{E}$ stands for the mean energy in the degrading target

$$
E=\frac{E_{i}+E_{f}}{2}
$$

The validity of approximation (1) is discussed in ref. $15 /$. The uncertainties in these energy measurements are discussed in refs. 14,7/. They are typically of the order of $\pm 2 \%$. 


\subsection{Results and discussion}

The stopping powers have been measured for 11 gaseous media for the projectiles $170^{8+}(84 \mathrm{MeV} / \mathrm{u}),{ }^{40} \mathrm{Ar}^{15+}(30 \mathrm{MeV} / \mathrm{u}),{ }^{40}{ }_{\mathrm{Ar}}{ }^{16+}(44 \mathrm{MeV} / \mathrm{u}),{ }^{86} \mathrm{Kr}^{29+}$ (43 MeV/u) and ${ }^{132} \mathrm{Xe}^{35+}(27 \mathrm{MeV} / \mathrm{u}) / 1 /$. Only the results for the ions $17_{0}$ and $132 \mathrm{Xe}$ which are representative of the extreme behaviours of stopping powers at GANIL energies are presented here. The stopping powers of gaseous media are plotted in Figs. 2 and 3 versus the stopper atomic number $z_{2}$ for ${ }^{17} 0$ and $132_{x}$ projectiles respectively. The values obtained for solid media with the same projectiles at the same energies $16,7 /$ are also plotted in these figures. These experimental values are compared with those from the simple assumption of fully stripped ions. This scaling law is derived from the standard relation used in most of the semi-empirical tabulations which consists in calculating the heavy ion stopping power $S_{\mathrm{HI}}$ from the ${ }^{4} \mathrm{He}$ one $\left(S_{\mathrm{He}}\right)$ at the same velocity through the effective charge parametrization :

$$
\frac{s_{H I}}{\gamma^{2} z_{1}{ }^{2}}=\frac{s_{H e}}{\gamma^{2} \mathrm{He}^{2} z_{\mathrm{He}}^{2}}
$$

In eq. (3) $z_{1}$ is the atomic number of the incident ion $\gamma_{\mathrm{He}}=1$ for the energies concerned here, $\mathrm{Z}_{\mathrm{He}}=2$ and the parameter $\gamma$ (effective charge parameter) is a function of the ion velocity, of $z_{1}$ and of the stopping medium atomic number $z_{2}$ 191 .

For fully stripped ions, the parameter $\gamma$ is equal to unity, then equation reduces to :

$$
s_{H I}=\frac{s_{H e}{ }^{z_{1}}{ }^{2}}{4}
$$

The $s_{H e}$ values are taken from Ziegler $/ 8 /$ (and are also tabulated in $/ 9 /$.

The solid lines drawn in Figs. 2 and 3 , correspond to this fully stripped assumption (T.E.). It can be seen that it leads to a fair agreement with the experimental data obtained for 17 o projectile at $84 \mathrm{MeV} / \mathrm{u}$ (see Fig. 2). From this figure, if we compare the data relative to solids and gases, we can conclude that the solid-gas effect, observed at low energy /10,11/, disappears when the projectile is totally stripped.

In figure 3 , i.e. for the data relative to the ${ }^{132} \mathrm{Xe}$ projectile at $25 \mathrm{MeV} / \mathrm{u}$, it can be seen that the fully stripped assumption leads to values about $20 \% \mathrm{higher}$ than the experimental ones for solid targets. This observation is consistent with the fact that the Xe ions outgoing the target are only partially stripped. Moreover, one car remark that the stopping powers of gaseous media are smaller than those measured in solid media. This solid gas effect is of the order of $20 \%$, in quantitative agreement with the results obtained at lower energies $110,11 /$ 


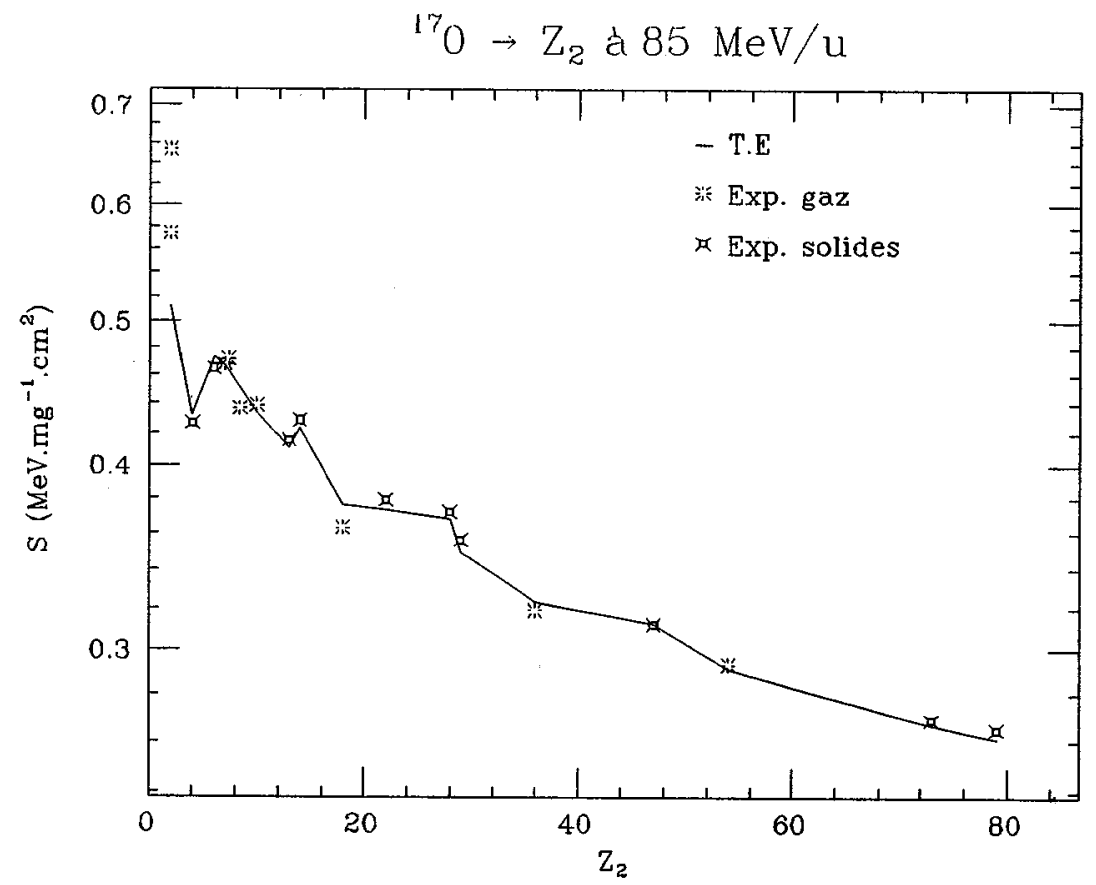

Fig. 2 : Stopping powers of solid and gaseous media (atomic number $z_{2}$ ) for $17_{0}$ ions at $85 \mathrm{MeV} / \mathrm{u}$. The solid line corresponds to the fully stripped assumption (T.E.).

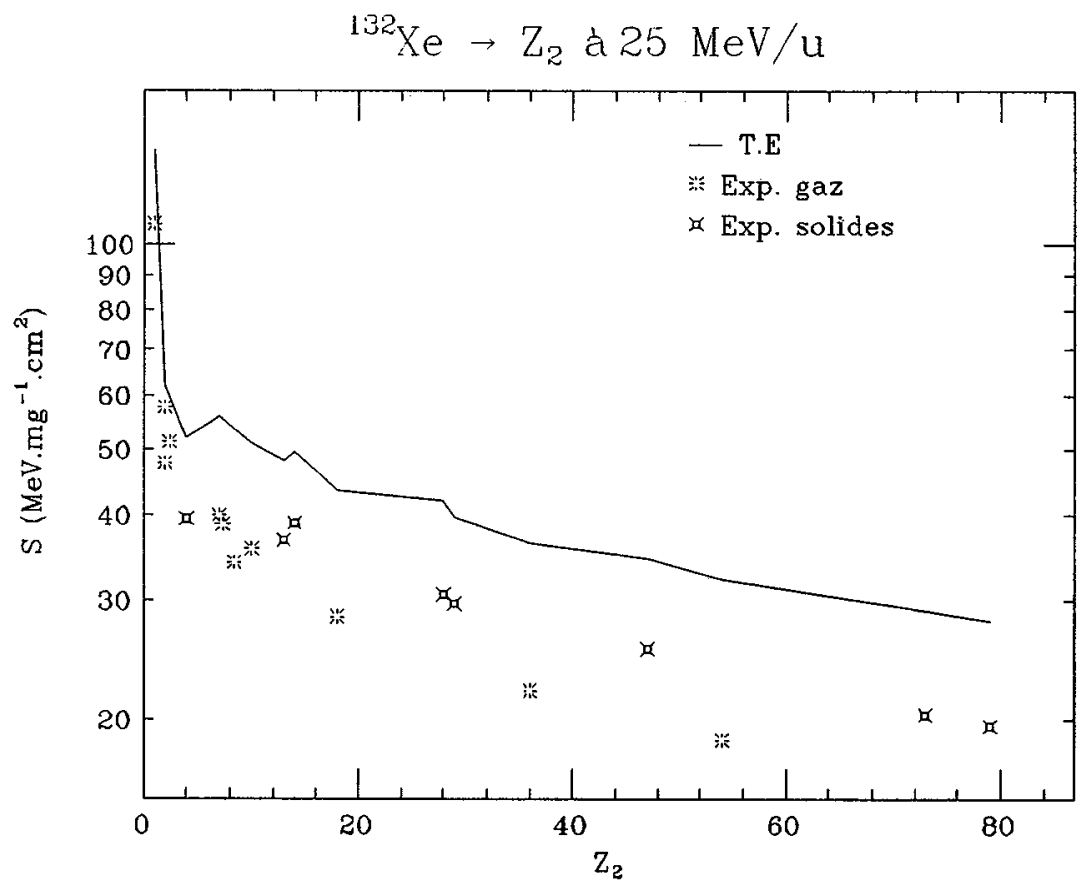

Fig. 3 : Same as Fig. 2 for ${ }^{132} \mathrm{Xe}$ lons at $25 \mathrm{MeV} / \mathrm{u}$. 
It follows from the analysis of these two extreme and of intermediate situations encountered with other ions and energies /1/, that the solid-gas effect is really linked to the ion charge state.

We have shown its persistence when the projectile is partially stripped and its vanishing when the ion is fully stripped. This observation is in agreement with the Bohr model /12/ which predicts a higher effective charge in solids than in gases due to a higher frequence of collisions.

\section{ENERGY LOSS STRAGGLING}

\subsection{Main contributions to the stragaling at intermediate energy}

The energy loss straggling in this velocity regime comes from two different contributions. The first one results from the statistical nature of the slowing down process by electronic collisions and the second from the statistical fluctuations of the ion charge state. At high energy, the first contribution can be expressed by the Bohr formula $/ 13 /$ :

$$
\Omega_{B}^{2}=49 Z_{1}^{2} z_{2} N \Delta X
$$

Here $z_{1}$ and $z_{2}$ denote the nuclear charge of the projectile and target atoms, respectively and $\mathrm{N} \Delta \mathrm{X}$ the number of target atoms per unit area.

With decreasing projectile energy, the assumption of free target electrons can no longer be valid, and refinement concerning the electron binding energies have to be included in the Bohr theory. Titeica /14/ worked out a more complete formulation which can be expressed /1/ by :

$$
\Omega_{T i}^{2}=\Omega_{B}^{2}+\frac{4}{3} E_{c i n} S_{B} \Delta X
$$

Here $E_{c i n}$ denotes the average electron kinetic energy in the stopping material and $S_{B}$ the stopping power of Bloch $/ 15 /$ which may be replaced by a stopping power value derived from experiment or tables.

The formula (5) is derived from the assumption of a constant charge $z_{1}$ of the moving ion. When the ion is partially stripped, an effective charge $\gamma Z_{1}$ must be used. However, the ion charge state fluctuates statistically. This phenomenon generates the second contribution to the energy loss straggling, $\Omega^{2} C^{*}$

This term can be calculated analytically /16/ if only two charge states are present (with a significant probability) during the ion passage through matter.

As the collisional and charge exchange energy loss distributions are independant (and approximatively gaussian) the total straggling is found by adding their 
variances :

$$
\Omega^{2}=\Omega_{T i}^{2}+\Omega_{C}^{2}
$$

\subsection{Experimental results and discussion}

The full width at half maximum (FWHM) of the beam energy distribution (denoted $\delta E)$ resulting from the absorber traversal is obtained from the difference

$$
\delta E^{2}=\delta E_{\text {total }}^{2}-\delta E_{\text {beam }}^{2}
$$

Where $\delta E_{\text {total }}$ and $\delta E_{\text {beam }}$ are respectively the FWHM measured on the beam profiles with and without absorber. Note that, for gaseous media, the term $\delta_{E}{ }^{2}$ beam takes into account the additional straggling in $\mathrm{Ni}$ windows.

The experimental results have been directly compared to the theory by plotting the ratio of the experimental straggling $\delta \mathrm{E}$ to the calculated collisional ( $\delta \mathrm{E}_{\mathrm{T}}$ or $\delta E_{B}$ ) as a function of the fraction of ion energy lost in the absorber. The results for ${ }^{16}$ o projectiles at $49.6 \mathrm{MeV} / \mathrm{u}$ are shown in figure 4 . One can remark

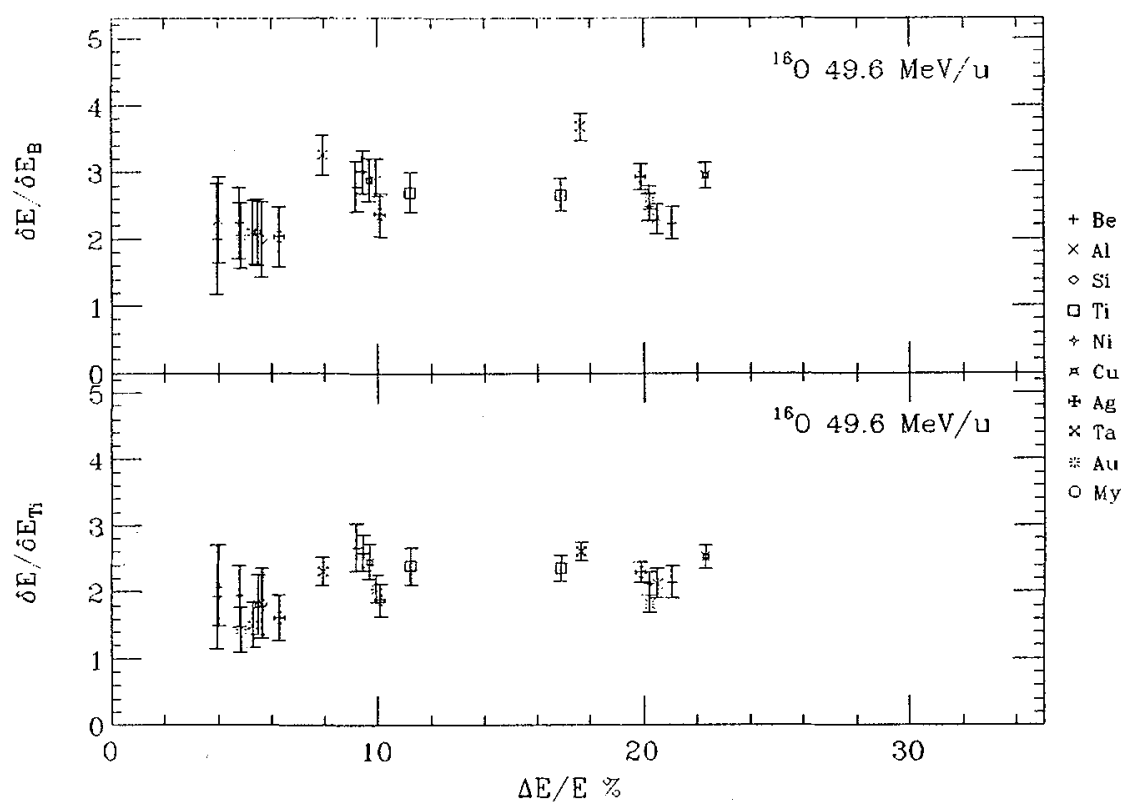

Fig. 4 : Ratio of the experimental energy straggling $\delta E$ (FWHM) for ${ }^{16} 0$ projectile at $49.6 \mathrm{MeV} / \mathrm{u}$ to the calculated collisional $\delta \mathrm{E}_{\mathrm{B}}$ or $\delta \mathrm{E}_{\mathrm{Ti}}$ versus the relative energy lost in the absorber. $\delta E_{B}$ refers to the Bohr's theory and $\delta E T$ to the Titeica formulation. Symbols of the different absorbers are given on the right side.

that the collision straggling is not sufficient to explain the experimental values. In this case, the charge exchange straggling cannot be involved because 
the projectile is totally stripped /7/. Moreover, it appears from these comparisons that the Titeica formula slightly reduces both the disagreement between theory and experiment and the dispersion of the points. This effect is especially obvious for heavy targets.

These discrepancies are not due to target inhomogeneities as can be seen in Fig. 5 in which identical ratio $\delta E / \delta E_{\mathrm{T}}$ are observed for $44 \mathrm{MeV} / \mathrm{u} 40 \mathrm{Ar}$ ions in gaseous and solid media.

The energy loss straggling has been measured for various ions and energies, and increasing values of the ratio $\delta \mathrm{E} / \delta \mathrm{E}_{\mathrm{T}} \mathrm{T}$ have been found when the ion is heavier and less energetic (see Fig. 6), i.e. less ionised. In order to evaluate the

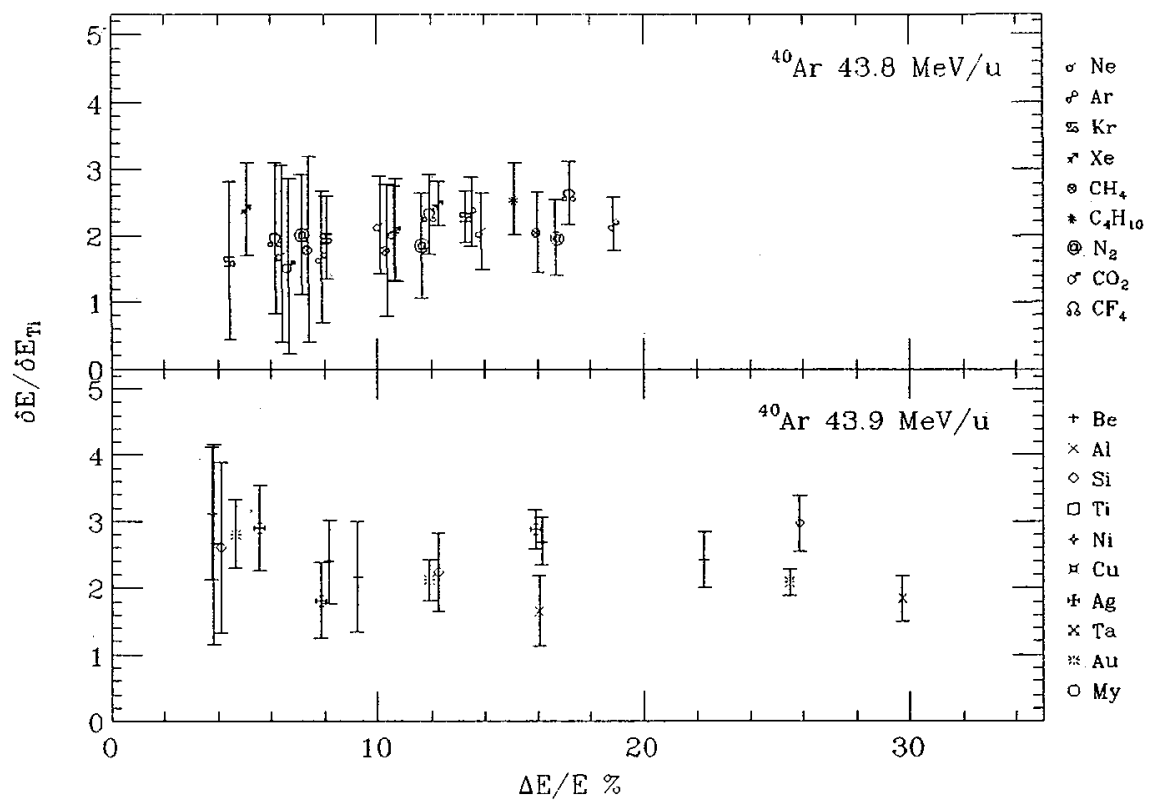

Fig. 5 : Ratio of the experimental energy straggling $8 \mathrm{E}$ for 40 Ar ions at 43.8 $\overline{M e V / u}$ to the calculated collisional $\delta \mathrm{E}_{\mathrm{Ti}}$ from the Titeica formulation versus the relative energy lost in the absorber. Upper part is relative to gaseous media and lower part to solid media.

influence of charge exchange straggling in these measurements, we have performed the Efken et al /16/ calculation, for ${ }^{86} \mathrm{Kr}$ projectile at an energy of $43 \mathrm{MeV} / \mathrm{u}$ on a $18 \mathrm{mg} . \mathrm{cm}^{-2}$ Be target. According to these authors, the charge exchange straggling $\delta E_{C}$ can be calculated if only two charge states $\left(q_{1}\right.$, $q_{2}$ ) are present with a significant probability. Its expression is given by :

$$
\delta E_{C}=2.355\left(\frac{s}{r_{1}}\right)\left(q_{1}^{2}-q_{2}^{2}\right)\left(2 \frac{F_{q_{1}} F_{q_{2}}}{\sigma_{q_{1}} \rightarrow q_{2}+\sigma_{q_{2}} \rightarrow q_{1}} x\right)^{1 / 2}
$$


Where $S$ is the stopping power, $\gamma^{Z}{ }_{1}$ the effective charge of the projectile, $F_{q 1}$, $F_{q 2}$ the fraction of the charge states $q_{1}$ and $q_{2}$, $\sigma_{q_{1} \rightarrow q_{2}}$ and $\sigma_{q_{2} \rightarrow q_{1}}$ the charge exchange cross-section, $x$ thickness of targets.

In the present case, the terms $F_{36}$ and $F_{35}$ are respectively equal to 0.75 and $0.25 / 1 \%$. The capture cross-section $\sigma_{36 \rightarrow 35}$ has been extracted from the Rozet et al values 117/. The electron loss cross section has been deduced from the capture one by assuming charge equilibrium. This leads to

$$
\begin{aligned}
& \sigma_{36 \rightarrow 35}=0.410^{-21} \mathrm{~cm}^{2} \\
& \sigma_{35 \rightarrow 36}=1.210^{-21} \mathrm{~cm}^{2}
\end{aligned}
$$

and to a $\delta \mathrm{E}_{\mathrm{C}}$ value of $16.5 \mathrm{MeV}$. The experimental value is $\delta \mathrm{E}=14 \pm 3 \mathrm{MeV}$. The collisional straggling $\delta E_{T i}=3.2 \mathrm{MeV}$, which must be added quadratically is negligible.

Therefore, we observe a good agreement between the charge exchange straggling deduced from Efken et al $/ 16 /$ and the experimental measurements. This phenomenon may be invoqued to explain the increasing ratio $\delta \mathrm{E} / \delta \mathrm{E}_{\mathrm{Ti}}$ from 2.1 for 160 to 5 for ${ }^{132} \mathrm{Xe}$ (Fig. 6). Nevertheless, in the case of totally stripped ions the observed ratio of the order of two is still unexplained.

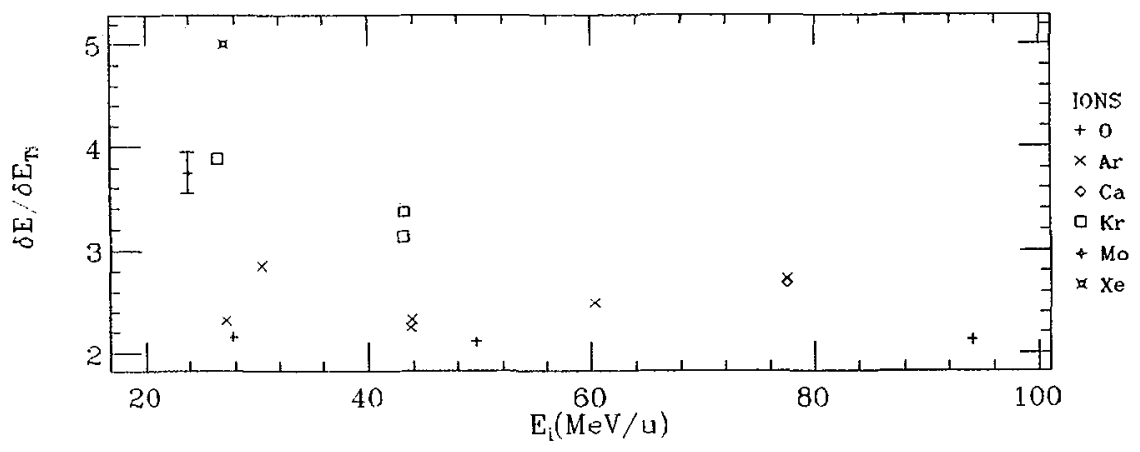

Fig. 6 : Evolution of the ratio $\delta E / \delta E_{T i}$ with the incident energy of the projectiles (symbols are given on the right ${ }^{\text {side). }}$

\section{CONCLUSION}

This general experimental study of heavy particle penetration through matter have permitted to measure several essential parameters, namely stopping power, energy straggling and angular straggling.

It has evidenced the vanishing of the gas-solid effect when the projectile is totally stripped. The energy straggling measurements have shown that the calculated collision straggling cannot explain the experimental values by itself even when the projectile is totally stripped. For partially stripped ions, the 
charge exchange effect seems to be able to account for most of the energy loss straggling. Finally the angular straggling measurements, which have not been presented here, have permitted to extend the scaling law established by sigmund et al $/ 18 /$ over five orders of magnitude $/ 2 /$.

These series of measurements constitute a set of parameters which permits to determine the average energy loss, energy loss straggling and angular straggling for heavy ions beams after their passage through matter over a wide range of energies. These predictions have a direct application for the conception and analysis of experiments using heavy ions beams in the intermediate energy domain ( 20 to $100 \mathrm{MeV} / \mathrm{u}$ ). They are also useful for testing stopping theories and models.

\section{REFERENCES}

/1/ HERAULT, J., Thesis Toulouse (1988).

/ 2 ANNE, R., HERAULT, J , BIMBOT, R., GAUVIN, H, , BASTIN, G., HUBERT, F., IPNO-DRE-88-09 (1988), Nucl. Instr. and Meth. B. (in press).

/3/ ANNE, R., BAZIN,D., MUELLER,A.C. , JACMART,J.C., LANGEVIN,M., Nucl. Instr. and Meth. A257 (1987) 215.

, 4 / BIMBOT, R., GAUVIN,H., ORLIANGE, I., ANNE,R., BASTIN, G., HUBERT,F , Nucl. Instr. and Meth. BI7 (1986)' 1 .

$15 /$ BIMBOT,R., DELLA-NEGRA, S., GARDES,D., GAUVIN,H., FLEURY, A. and HUBERT,F . Nucl. Instr. and Meth. 153 (1978) 1 .

161 GAUVIN,H., private communication (1988).

17 GAUVIN, H. , BIMBOT,R., HERAULT,J , ANNE, ., BASTIN, G. , HUBERT,F., Nucl. Instr. and Meth. B28 (1987) 191 .

18/ ZIEGLER,J.F., The stopping and ranges of ion in matter, vol. 5 (Pergamon Press, Randon 1980).

191 HUBERT, F., FLEURY,A., BIMBOT,R., GARDES,D., Ann. Phys. (Paris) 5 supp. (1980) 1 .

$110 /$ GEISSEL,H. , LAICHTER, Y, SCHNEIDER,W.F.W. , ARMBRUSTER,P., Nucl. Instr. and Meth. 194 (1982) 21 .

/11/ ORLIANGE, I., Thesis Orsay (1985).

/12/ BOHR,N., LINDHARD,J., Dan. K. Vidensk. Selsk. Mat. Fys. Medd. 26.13 (1954).

/13/ BOHR,N., Dan. K. Vindensk. Selsk. Mat. Fys. Medd. 18.8 (1948).

114/ TITEICA,S., Bull. Soc. Rou. Phys. 38 (1939) 81.

/15/ AHLEN, S.P., Rev. Mod. Phys: 52.1 (1980) 121.

/16/ EFKEN, B., HAHN, D. , HILSCHER. L. and WUSTEFELD,G, Nucl. Instr. and Meth. 129 (1975) 219 .

$117 /$ ROZET, J.P., CHETIOUI,A., BOUISSET,P. , VERNHET,D., WOHRER,K., TOUATI,A., STEPHAN,C., GRANDIN, J.P., Phys. Rev. Lett. 58.4 (1987) 337.

$118 /$ SIGMUND,P., WINTERBON,K.L.B., Nucl. Instr. and Meth. 119 (1974) 541. 